\title{
CAR-AOKE: VOCAL PERFORMANCES INDICATE DISTRACTION EFFECTS OF IN-CAR MUSIC
}

\author{
Warren Brodsky \& Matan Ziv \\ The Music Science Lab, Department of the Arts \\ Ben-Gurion University of the Negev, Beer-Sheva, Israel \\ wbrodsky@bgu.ac.il
}

\begin{abstract}
Summary: Drivers engage in a host of driving-unrelated tasks while on the road. Most frequently, drivers listen to music and sing-along with the words in a karaoke fashion. At times drivers accompany songs by pounding-out drum-kicks, fingering guitar-licks, singing background, and even dancing in their seat. However, there is controversy over in-cabin music: Does background music facilitate driver performance via increased arousal leading to more focused concentration, or cause distraction placing drivers at greater risk. In an effort to shed light on the debate over the utility of in-car music, the current study explored how driving tasks might subsequently affect vocal performances during simulated driving. Eighteen young drivers recorded two versions of two songs (baseline vs. low-demand $v s$. high-demand driving). The results indicate that as the perceptual demands of the primary driving task increase, the performance of the secondary activity (i.e., karaoke-like singing) declines. That is, vocal performances during high-demand driving contained significantly more errors of both intonation/rhythm and lyrics compared to low-demand driving, while both were far less accurate than baseline recordings. Such a picture supports evidence that engaging in music activity does actually preoccupy vital mental resources. In-car music may not necessarily be handled very well, nor is it blocked-out entirely by drivers during high-demand driving - as previously reported in some literature. Singing along with in-cabin music background may contribute to increased risk for incidents, events, and near-crashes, and should be reconsidered by traffic scientists investigating human factors, vehicular control, and road safety.
\end{abstract}

\section{INTRODUCTION}

Drivers engage in a host of driving-unrelated tasks while on the road. Drivers report they very often listen to music and sing-along to the words in a karaoke fashion while driving in traffic. At times they even accompany the songs they listen to by pounding-out drum-kicks and syncopated rhythms on the steering-wheel, playing licks and solos in an air-guitar fashion, vocalizing background fills and runs, and even dancing in the driver's seat. However, there is a controversy about in-cabin music. For example, Unal and colleagues (Unal, Steg, \& Epstude, 2012; Unal, de Ward, Epstude, \& Steg, 2013; Unal Platteel, Steg, \& Epstude, 2013) claim that in-car music facilitates driver performance via increased arousal leading to a more focused concentration, and that drivers implement cognitive strategies to reduce task-demands on the road by blocking-out auditory distracters such as music and radio broadcasting. Therefore, Unal and colleagues conclude that in-car music does not impair driving performance. Dibben and Williamson (2005) claim that unlike conversation with local passengers or distant callers which require the driver to sustain a necessary level of attention throughout, singing to music played in the car allows 
drivers the flexibility to start and stop at will with no ill consequences. On the other hand, Hughes, Rudin-Brown and Young (2013) found that singing while driving alters driving performance and impairs hazard perception, while Brodsky $(2002,2015$; Brodsky \& Kizner, 2012; Brodsky \& Slor, 2013), demonstrated that background music causes distraction and places drivers at greater risk for increased driver miscalculation, inaccuracies, deficiencies, errors, traffic violations, and driver aggressiveness. These later studies present evidence that music activity clearly hampers perceptual motor control leading to decrement of vehicular performance with increased incidents, events, and near-crashes.

It should be pointed out that all research efforts thus far have investigated how engaging with incabin background music affects driving behavior and vehicular control; these studies employ computerized simulated driving, closed-circuit test-tracks, and real world on-road 'naturalistic' driving. Such a stance is inherited from studies exploring in-car cell-phone use, as well as those investigating the effects of conversation. Among the later studies, Crundall, Bains, Chapman, and Underwood (2005) examined how drivers adapted to the flow of conversation on urban roads; they found that such adaptation (referred to as conversational suppression) reflects a higher level of traffic demand and control, and demonstrates the degree to which secondary activities impinge on the primary driving task. Therefore, it would also seem warranted to explore how driving tasks might subsequently affect vocal performances (i.e., singing songs) as this avenue might shed light on the debate over the utility of in-car music activity. It is hypothesized that as the perceptual demands of the primary driving task increase, car-aoke (i.e., singing-along to music while driving) will decline. The study questions if drivers experiencing higher demand driving conditions simply discontinue singing at will with no ill-consequences, and/or block-out the background song-stimuli altogether in their attempt to cope with driving tasks. Or, in their effort to preserve the primary driving task, do drivers prioritize undertakings related to driving by concurrently disrupting the irrelevant activity, and as they are unable to block-out the aural background, demonstrate persistent suboptimal vocal performances.

\section{PRE-STUDY DEVELOPMENT}

The study employed three well-known popular songs that everyone from the target sample could easily sing. Initially, pop-music radio song-charts were employed to enlist a set of suitable songs. However, several problems with these exemplars arose, including the facts that most music charts contain songs from specific years that are not necessarily relevant to a target sample of young adults, that songs from the latest song-charts are not necessarily as popular (or well known) as other 'classic' pop/rock songs of previous years, and that songs ranked high in the popular music charts are not necessarily suitable to sing along with. Therefore, a list of eleven songs based on five criteria was assembled, and presented to 75 young adults with comparable demographics as the target sample. These criterion were: (a) Language - local Hebrew vernacular; (b) Popularity - recorded by well-known Israeli artists or ensemble groups, and appear on a best-selling album; (c) Complexity - simple structural form (introduction, verse, chorus, verse, chorus, coda); (d) Diapason - within a vocal range not extending beyond one-anda-half octaves; and (e) Vocal Rendition - lack of elongated instrumental solo void of song text. These criteria are similar to those used by Hughes, Rudin-Brown, and Young (2013). The participants of the survey were undergraduates from a Faculty of Humanities and Social Sciences between the ages of 20-30 years old $\left(M_{\text {Age }}=24.97, S D=2.01\right)$, with a biased $(+=73 \%)$ gender 
proportion (although this proportion is similar to the registry of students in the Faculty). All participants received extra course credit. The on-line survey was developed with Qualtrics. Each participant was required to rank the popularity of eleven songs on a 4-point scale $(1=$ 'Not At All Popular or Well-Known'; 4 = 'Highly Popular and Well-Known'). In addition, each participant had the opportunity to suggest the name of another song, that in their opinion was more popular and well-known than the eleven titles listed. Although no time limit was imposed, the maximum time taken to complete the survey was ten minutes. See Table 1.

Table 1. Results of Song Survey

\begin{tabular}{lllll}
\hline & Song Title & Artist / Band & \multicolumn{2}{l}{ Ranking } \\
\cline { 3 - 4 } & & MN & SD \\
\hline 1 & Ani Ve'ata & Arik Einstein & 3.80 & 0.49 \\
2 & Oof Gozal & Arik Einstein & 3.76 & 0.52 \\
3 & Ve'ech Shelo & Ariel Zilber & 3.65 & 0.58 \\
4 & Badad & Zohar Argov & 3.60 & 0.70 \\
5 & Yom Shishi At Yoda'at & Bezin Band & 3.59 & 0.68 \\
6 & Roni & Gazoz Band & 3.48 & 0.70 \\
7 & Shuvi El Beiti & Idan Raichel & 3.40 & 0.68 \\
8 & Shlach Li Malach & Mashina Band & 3.28 & 0.79 \\
9 & Tagidi & Shlomo Artzi & 3.27 & 0.78 \\
10 & Galshan & Gazoz Band & 3.24 & 0.90 \\
11 & Nitsotsot & Fortis \& Saharov & 3.11 & 0.80 \\
\hline
\end{tabular}

As can be seen in Table 1, the popularity of the songs was high (Range =3.11-3.80), with the average popularity ranked $3.47(S D=0.21)$. The most popular Top-3 songs were selected as stimuli for the current study.

\section{THE STUDY}

\section{Methods}

Participants. Twenty-nine undergraduates from a Faculty of Humanities and Social Sciences participated. The criteria put in place to participate, were: (a) Drivers License - certified as valid for at least three years; (b) General Health - declaration that no pharmaceutical intervention for hyperactivity or high blood pressure had ever been prescribed; and (c) Sing-ability - willingness to sing during simulated driving. During the study seven participants were dropped from the sample. In one case there was a technical failure, in another the participant could not remember the lyrics, three participants were not able to complete one of the driving tasks within a reasonable amount of time, one suffered from simulator sickness (involving dizziness/nausea), and one participant requested to discontinue participation within the first 10-minutes of the active experiment. The remaining 22 participants were between 23-29 years old $\left(M_{\text {Age }}=25.73\right.$, $S D=1.40)$, with more females $(64 \%)$ in the sample. On average the participants held a certified Drivers License for an average 7.36 years $(S D=1.87)$. By self report, none of the participants had previously been charged with a traffic offense requiring a period of probation or cancellation of their license. While $27 \%$ claimed they had never been in an accident, $58 \%$ reported to have been involved in 1-2 incidents (referred to as a 'fender-bender'). The overriding majority of the participants ( $86 \%$ ) stated that they 'always' listen to music when driving: $90 \%$ reported they listen to songs described as 'fast' or 'extremely fast-paced', and $90 \%$ stated that they reproduce music in the vehicular cabin at levels considered to be 'loud' or 'very-loud' intensities. Most 
specifically, $86 \%$ claimed that 'most of time' they drive while singing along with the songs heard in the background from audio sources including music radio broadcast, CDs, and MP3 players. It should be pointed out that these undergraduates were not music majors; $68 \%$ reported to have never had previous music experience. Among the $31 \%$ who claimed to have had music training, the majority $(77 \%)$ learned an instrument during childhood for an average 2.41 years $(S D=4.27)$ with either a private instrument teacher or at a neighborhood music school.

Equipment. The study employed a PC-controlled driving simulation task involving singing along with music heard in the background. Simulated driving was conducted via the Midtown Madness 'Chicago Edition' (Microsoft) software, in a single-user cruise mode with limited vehicles on the road, emulating a New Beetle (Volkswagen) cockpit with realistic dashboard digital speedometer, gauges, and rearview mirror. The software was run on a desk-top PC with a 17" flat monitor (Compaq), coupled to a $M O M O^{\circledR}$ Force Feedback Racing steering wheel with accelerator and brake pedals (Logitech). All aural signals, including environmental driving sounds (vehicle and roadway), the background music, and the drivers' own vocal performances, were routed and subsequently equalized with a 5-channel mini mixer (Samson) through a 4channel mini stereo headphone amplifier (Samson) to $R H-5 M A$ full-frequency $(20 \mathrm{~Hz}-20 \mathrm{kHz})$ supra-aural (40mm speakers) closed-back monitor headphones (Yamaha). The drivers' vocal performances were captured with an $H 2$ handy digital recorder (Zoom) to SD memory cards as 24bit/96kHz linear PCM (.wav) files. The background music (MP3 files) was controlled and reproduced via an $i M a c$ (Apple) desktop computer.

Music Stimuli. Three songs (Nos. 1-3, Table 1) were used in the study. These songs were performed by one of two male vocal artists, with pop-ensemble accompaniment (i.e., piano, guitar, bass, and drums). On average, the songs were four minutes duration ( $M_{\text {Minutes }}=3: 58, S D=$ 0.56 , Range $=3: 20-4: 20)$, with about 100 words $(M$ Words $=98, S D=27$, Range $=71-127)$, and roughly 200 notes in the melody line $\left(M_{\text {Notes }}=215.33, S D=63.13\right.$, Range $\left.=150-276\right)$.

\section{Procedure}

Two nights before the actual experiment, each participant received the lyrics of the songs and a YouTube web-link for each song (in a similar fashion as employed by Hughes, Rudin-Brown, \& Young, 2013). The participants were instructed to practice each song several times during the two days leading up to the active experiment. The study was conducted in an acoustically treated Music Psychology lab. Upon arrival to the lab every participant signed an Informed Consent Form, and completed a 1-page demographic questionnaire. The participants were requested to choose two of the three songs to be used in their particular experiment, to place the headphones over their ears, and begin singing a full rendition of each song along with the same YouTube video clip accompaniment that they had practiced with previously; they sang from memory without the texts in front of them. The participants were told that no one, not even the experiment monitor, could hear them sing as they were isolated behind a soundproof glass partition - with the experiment monitor clearly in sight on the other side of the partition. However, they were notified that their vocal performances would be recorded as audio files for later analyses. The recordings were made in such a way as to detach each participant's singing from all other aural stimuli - including the background music accompaniment. This strategy was employed in an effort to preserve isolated vocal performances. During this phase the computer 
monitor was turned off (i.e., black screen). The vocal performances of the two songs were performed in a random order; these renditions served as Baseline versions. After recording the two vocal performances, the computer monitor was switched on; the participants viewed a traffic scene with moving vehicles, walking pedestrians, active traffic lights, and other environmental street sounds. A short oral briefing about the simulator (steering wheel, pedal controllers) ensued, and then regulations about traffic were outlined (driving in the right lane, stopping for red lights, obeying traffic signs, not exceeding a maximum speed of 50mph). Finally, every participant received a 5-minute practice of simulated driving.

The experiment was carried out as two trials (reflecting two driving conditions) counter-balanced across the sample. In each condition the participants were asked to sing along with one of the two songs in its entirety until the trial ended; the songs were employed in a counter-balanced manner (albeit juggled between three songs across the sample). One trial consisted of lowdemand driving whereby participants freely cruised throughout the city-center streets of Chicago while singing one of the songs; this trial ended upon conclusion of the song. The second trial consisted of high-demand driving in which each participant was required to navigate throughout the city-center to a destination plotted on one of two A4-size city maps placed to the right of the computer monitor. The two maps (each indicating one of the two destinations) were also counter-balanced across the sample. It should be noted that in the right lower quadrant of the monitor was a small ( $2.5 \times 2.5$ inch) window with an animated GPS application that allowed the drivers to check their progress and location in real time as compared to the printed map. Before each high-demand trial, one of the two songs began playing in the background, to which drivers were instructed to sing along continuously throughout the entire trial until they arrived at the designated location. It should be noted that the song was heard continuously in a looped fashion until reaching the final destination; the majority of drivers $(77 \%)$ required $2-3$ repetitions of the song (singing throughout) before arriving at the designated location.

\section{Results}

The overriding goal of the study was to compare between the two vocal performances per driving condition (baseline vs. low-demand, baseline vs. high-demand), as well as to contrast the two driving conditions themselves. Such analyses required the examination and scoring for errors of the sung notes (inaccuracies of intonation, rhythm, and tempo) as well as for errors of the sung lyrics (inaccuracies of the text by word-replacement or neglect). This musicological evaluation was undertaken by an independent music expert who was both blind to the goals of the study, as well as to the fact that vocal performances were recorded during simulated driving. The adjudicator was a 56-year-old professional musician with absolute hearing; his background includes 51 years experience as a pianist, 36 years experience accompanying vocalists at auditions, and most importantly, 35 years experience as a répétiteur. A répétiteur is the pianistaccompanist responsible for coaching singers during music and production rehearsals. As a vocal coach, the répétiteur is responsible for advising singers on how to improve their pitch and pronunciation, as well as for correcting errors of notes (intonation), phrasing (rhythm), and text (lyrics).

After aural examination each sound file, and marking perceived errors on the music notation lead sheet for each performance, the data from all participants with scores indicating $>90 \%$ errors (of 
intonation and rhythmic properties) at baseline were removed from the set. This strategy assured that effects of the study reflect differences between driving conditions with the least amount of corruption by drivers who consistently sing out-of-tune (also referred to as tone-deafness). Such inabilities might indicate problems of processing and/or distinguishing between tones, as well as deficit in accurately reproducing vocal pitches (i.e., consistently singing $1 / 10^{\text {th }}$ above/below the precise pitch). As a result, the data of four drivers was removed from the study, leaving 18 subjects in all subsequent analyses. Initially, errors of intonation and rhythmic properties, as well as lyrics, were calculated and then reconfigured as percentages. See Table 2.

Table 2. Errors (\%) Of Vocal Performances

\begin{tabular}{|c|c|c|c|c|c|c|c|}
\hline & \multicolumn{2}{|c|}{ Baseline } & \multicolumn{2}{|c|}{ Low-Demand } & \multicolumn{2}{|c|}{ High-Demand } & \multirow[t]{2}{*}{ Sig } \\
\hline & MN \% & $\mathrm{SD}$ & MN \% & SD & MN \% & SD & \\
\hline \multicolumn{8}{|l|}{ Song \#1 } \\
\hline Intonation & 38.29 & 22.91 & 31.22 & 20.03 & & & $<0.09$ \\
\hline Lyrics & 09.60 & 08.03 & 12.42 & 08.05 & & & $<0.05$ \\
\hline \multicolumn{8}{|l|}{ Song \#2 } \\
\hline Intonation & 28.17 & 17.25 & & & 32.89 & 17.15 & $<0.05$ \\
\hline Lyrics & 07.23 & 05.64 & & & 15.82 & 10.30 & $<0.01$ \\
\hline
\end{tabular}

To answer the question if driving tasks might cause driver distraction and ill-effects on Car-aoke vocal performances (i.e., draining of mental efforts needed to sing well-known and highly familiar songs), the error percentages of vocal performances were entered into two repeatedmeasures analyses of variance. The results indicate that vocal performances during low-demand driving were slightly more in-tune and in-rhythm than baseline versions - although as these did not achieve statistical significance such differences might simply reflect noise among the data $\left(F_{(1,17)}=3.35, M S e=130.45, p=0.084, \eta_{\rho}^{2}=0.17\right)$; nevertheless, the lyrics contained significantly more errors during driving $\left(\mathrm{F}_{(1,17)}=7.92, M S e=9.00, p=0.012, \eta_{\rho}^{2}=0.32\right)$. Further, compared to baseline recordings, vocal performances during high-demand driving were significantly more out-of-tune with significantly less rhythmic precision $\left(F_{(1,17)}=5.10, \mathrm{MSe}=\right.$ $\left.39.80, p=0.038, \eta_{\rho}^{2}=0.23\right)$, and the lyrics contained significantly more errors $\left(F_{(1,17)}=14.41\right.$, $\left.M S e=46.06, p=0.0014, \eta_{\rho}^{2}=0.46\right)$. Then, to answer the question if there are differences of vocal performances between the two driving conditions (low-demand vs. high-demand driving when compared to baseline), delta $(\Delta)$ change variables were calculated and entered into a repeated-measures analysis of variance. These results indicated that vocal performances during high-demand driving were significantly more corrupted for both intonation and rhythm $\left(F_{(1,17)}=\right.$ $\left.6.58, M S e=187.23, p=0.0201, \eta_{\rho}^{2}=0.28\right)$, as well as for lyrics $\left(F_{(1,17)}=5.07, M S e=59.24, p=\right.$ $\left.0.038, \eta_{\rho}^{2}=0.23\right)$.

\section{CONCLUSIONS}

Drivers report they very often listen to music and sing along with the words in a karaoke-like fashion while driving in traffic. Nevertheless, there is disagreement in the literature concerning in-cabin music as to whether or not engagement facilitates driver performance or alters driving performance and impairs hazard perception. Furthermore, there is an ongoing debate if drivers self-implement strategies such as stopping music engagement at will with no ill-consequences or even block-out auditory distracters (concluding that in-car music does not impair driving performance), or if background music causes distraction and increased risk (concluding that in- 
car music prompts driver deficiencies and aggressiveness leading to increased incidents, events, and near-crashes). For a comprehensive review see Brodsky (2015). The current study found that vocal performances during low-demand driving were slightly better than when singing alone (baseline); perhaps such a find relates to a positive 'fun' experience drivers have when singing while freely cruising about - albeit the lyrics sung contained significantly more errors. Yet, vocal performances during high-demand driving were significantly more out-of-tune with significantly less rhythmic control, and the lyrics sung contained significantly more errors. Namely, vocal performances during high-demand driving were significantly more corrupted than low-demand driving. These findings offer further evidence regarding the utility of in-car music: Car-aoke - as a secondary activity to driving - may deplete a portion of the mental resources required for safely driving a car. One can only wonder if such significant effects surfaced from a relatively small sample using PC-controlled simulated driving as in the current study, then how much more hazardous are the effects of Car-aoke in a real-world traffic road environment.

\section{REFERENCES}

Brodsky, W. (2002). The effects of music tempo on simulated driving performance and vehicular control. Transportation Research, Part F: Traffic Psychology And Behaviour, 4, 219-241.

Brodsky, W. (2015). Driving With Music; Cognitive-Behavioral Implications. Human Factors In Road And Rail Transport Series. London, UK.: Ashgate Publishing Ltd.

Brodsky, W., \& Kizner, M. (2012). Exploring an alternative in-car music background designed for driver safety. Transportation Research, Part F: Traffic Psychology And Behaviour, 15, 162-173.

Brodsky, W., \& Slor, Z. (2013). Background music as a risk factor for distraction among youngnovice drivers. Accident Analysis \& Prevention, 59, 382-393.

Crundall, D., Bains, M., Chapman, P., \& Underwood, G. (2005). Regulating conversation during driving: a problem for mobile phones. Transportation Research, Part F: Traffic Psychology And Behaviour, 8, 197-211.

Dibben, N., \& Williamson, V.J. (2007). An exploratory survey of invehicle music listening. Psychology Of Music, 35, 571-590.

Hughes, G.M., Rudin-Brown, C.M., \& Young, K.L. (2013). A simulator study of the effects of signing on driving performance. Accident Analysis and Prevention, 50, 787-792.

Unal, A.B., de Ward, D., Epstude, K., \& Steg, L. (2013). Driving with music: effects on arousal and performance. Transportation Research, Part F: Traffic Psychology And Behaviour, 21, $52-65$.

Unal, A.B., Platteel, S., Steg, L., \& Epstude, K. (2013). Blocking-out auditory distracters while driving: a cognitive strategy to reduce task-demands on the road. Accident Analysis and Prevention, 50, 934-942.

Unal, A.B., Steg, L., \& Epstude (2012). The influence of music on mental effort and driving performance. Accident Analysis and Prevention, 48, 271-278. 